\title{
Reasons Early Career Black Special Education Teachers Quit Their Positions
}

\author{
LaRon A. Scott \\ Department of Counseling \& Special Education, Virginia Commonwealth University
}

\begin{abstract}
Special education policymakers and practitioners are concerned about attrition among teachers, especially those who leave ear-

ly in their careers and teachers of color. To increase knowledge about attrition, I examined demographic and interview data from 10 Black teachers who quit their positions before they completed

their probationary periods (1-3 years). Guided by Cox's (1994) cultural diversity in organization model designed to capture the complex nature of diversity in organizations, I used phenomenological research methods to better understand the teachers' experiences surrounding the decision to quit. The qualitative analyses revealed four themes: (a) inadequate mentoring, (b) role abuse, (c) cultural insensitivity, and (d) inadequate resources. I conclude with suggestions for education policies and practices at the local and federal level that special educators can employ to address these issues. This paper highlights issues of attrition within a subgroup of educators (Black special educators) that are underrepresented in the research literature.
\end{abstract}

*Correspondence to Author: LaRon A. Scott Department of Counseling \& Spewealth University

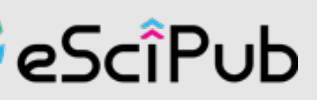

eSciPub LLC, Houston, TX USA.

Website: https://escipub.com/

Keywords: special education; teacher education; teacher attri-

How to cite this article:

LaRon A. Scott. Reasons Early

Career Black Special Education Teachers Quit Their Positions. American Journal of Educational Research and Reviews, 2020,5:79. tion; teacher retention; Black special education teachers 


\section{Reasons Early Career Black Special Educa- tion Teachers Quit Their Positions}

Recruitment and retention of special education teachers from underrepresented racial groups (e.g., Black) was identified as a critical research and practice goal during the 2015 National Goals Conference for the American Association for Individuals with Intellectual Disabilities (Thoma et al., 2015). For the past 40 years, a consistent finding is that teachers of color represent approximately $12-20 \%$ (i.e., Blacks only $6.7 \%$ ) of the teacher workforce (Carver-Thomas, 2018), yet students of color comprise nearly $50 \%$ of students with disabilities (National Center for Educational Statistics, 2019). Thus, the short supply of special education teachers, and mainly those of color, is a particularly pressing issue.

Why does it matter that we recruit and retain more teachers of color, especially special educators? Teachers of color benefit students from different racial backgrounds (e.g., Egalite, Kisida, \& Winters, 2015) in various ways. For example, a recent study found that middle school students of all races rated teachers of color (e.g., Black and Latinx) as more motivating, supportive, and caring than White teachers (Cherng \& Halpin, 2016). Additionally, researchers found that teachers who shared similar racial/ethnic background with their students served as positive role models (Henfield, 2013), and contributed to positive school outcomes, including higher student achievement (Dee, 2004; EastonBrook, 2019; Egalite \& Kisida, 2018; Redding, 2019), decreased dropout rates (Gershenson et al., 2017), and reduced suspension and expulsion of Black students (Lindsay \& Hart, 2017). For Black students in special education, who represent a larger proportion of students identified as special needs (16\%) compared to their proportion in the school population $(15 \%$; National Center for Education Statistics, 2019), having access to a Black special education teacher can make an important difference during their kindergarten through 12th-grade experience. For instance, Black students are often identified and referred for special education services based on the perceptions and recommendations of professionals who misinterpret the Black cultural nuances (Jones-Goods \& Grant, 2016). Therefore, racial and cultural differences among teachers and students may contribute to the over-referral and disproportionate number of students of color in special education (Cartledge, Gardner, \& Ford, 2009; Ford, 2012). One solution to help Black students in special education would be to increase the number of Black teachers in both general education and special education.

\section{Special Education Teacher Attrition}

Special education teachers leave their position each year at a rate $46 \%$ more higher when compared to general education teachers (CarverThomas \& Darling-Hammond, 2017), and teachers of color have the highest rate of turnover (Achinstein et al., 2011). However, the results of investigations regarding special education teacher attrition do not always match the reasons teachers of color leave teaching. Typically scholars have focused on either attrition as it pertains to teacher occupation (general or special education) or race, rather than aggregating the data to examine multiple categories together, with specific attention to the reasons for Black special education teachers leaving the field (Boe et al., 2008). This failure to aggregate data and report findings may obscure differences between general and special educators' attrition when race is a factor (Haberman, 2004; Scott et al., 2020). For example, Haberman (2004) reported that when compared to White teachers, teachers of color might leave the profession for different reasons, including: (a) school culture (e.g., cultural imperialism, curriculum content, higher frequency of suspension of students of color); (b) the undue stress it causes Black teachers being considered spokespeople for Black perspectives and issues that may arise in their schools; (c) unfair testing and evaluation of students of color causing high levels of stress for teachers, and; (d) the short supply of these teachers within schools and school systems who 
can provide support to other teachers of color. Additionally, Black educators are susceptible to microaggressions, unconscious bias, and assumptions of incompetence by white colleague's which points to additional factors about fit in predominately white academic environments (Gutierrez y Muhs, et al., 2012; Cormier \& Scott, in press). A better understanding of the reasons for leaving, by combining factors such as race and professional role, may yield clues as to how to develop effective recruitment and retention practices.

Overall the annual teacher attrition rate is $8 \%$ (Carver-Thomas \& Darling-Hammond, 2017), particularly for new teachers, with rates almost six times the annual teacher attrition rate for special education teachers (46\%; Carver-Thomas \& Darling-Hammond, 2017). Using survey data from the 2007-2008 Schools and Staffing Survey, Conley and You (2016) found that poor administrative support, low teacher team efficacy, low teacher job autonomy, poor socio-economic/human conditions, and student disengagement were common predictors of special education teachers' intentions to leave the profession. In an analysis of studies used to investigate factors that contribute to special education teacher attrition, Billingsley \& Bettini (2019) noted a number of factors that predicted special education teachers' decisions to leave the field. Some of these factors included: (a) personal circumstances and priorities; (b) work environment factors (e.g., working conditions, lack of administrative support, role problems); (c) negative affective reactions (e.g., work-related stress and job satisfaction); (d) age; (e) and teacher certification status (Billingsley \& Bettini, 2019). However, as noted in studies by Conley and You (2016) as well as in a study by Billingsley (2019), the relationship between race and attrition required additional research, as combined factors about special education teachers, race and attrition lacked empirical investigation.

\section{Race Comparisons with Special Education Teacher Attrition}

In addition to the factors identified by Conley and You (2016), and Billingsley \& Bettini (2019), other research exists corroborating the range of factors that lead to special education teacher attrition. These factors include lack of administrator support (Skaalvik \& Skaalvik, 2007), lack of time and resources to adequately do their jobs (Adera \& Bullock, 2010), increased amounts of paperwork (e.g., Individualized Education Program related paperwork) that special educators are required to manage (Vannest \& HaganBurke, 2010), and student behaviors (Hastings \& Brown, 2002). However, none of the researchers identified whether these attrition factors were directly linked to Black special education teachers.

Ingersoll and May's (2011) examination of teacher recruitment and retention-found that teachers of color reported greater dissatisfaction with their jobs compared to White teachers. Though personal and family factors also influenced reasons that teachers, regardless of race, left their positions, teachers of color cited dissatisfaction as a reason more often compared to their White counterparts. Ingersoll and May (2011) did not control for teacher role (special or general education) as a factor in their study; therefore, questions remained regarding whether the findings applied to Black special education teachers. Further, Moore (2012) discussed the relationship between school environments and teacher dissatisfactions and disclosed findings suggesting that Black teachers were more likely to be dissatisfied with their teaching jobs compared to non-Black teachers. Although Moore was unable to explain the phenomenon, it is noted that additional studies were necessary to determine the underlying factors that caused a higher level of dissatisfaction, particularly considering the need to retain more Black teachers. Moore called for more qualitative studies to isolate concerns and challenges of Black teachers that influence job dissatisfaction. Despite the fact Moore included special education teachers, the overall sample was comprised of a mix of teachers (e.g., general and 
special education), from kindergarten through 12th grade, and Moore did not exclusively focus results and findings on the issues and challenges of Black special education teachers.

\section{Conceptual Framework}

In the current study, I used Cox's (1994) cultural diversity in organizations (CDO) model to establish how barriers, placed on teachers of color by the majority culture, may obstruct professional growth. Madsen and Mabokela (2000) explained that "the culture within an organization strongly influences how minorities will be treated by their European American counterparts" (p. 850). Cox (1994) posited that interactions in an organization (e.g., a person's work environment) based on a person's affiliation, such as a person's race, could lead to experiences that affect work outcomes. Thus, relations between the majority and minority group within a person's environment can affect work outcomes, and can be analyzed on the following three levels: (1) individual, (2) group/intergroup, and (3) organizational. Therefore, the effect of cultural diversity (e.g., race) within the organization must be understood from all three levels (Cox, 1994). In applying all three levels to the effects of the current study, I am suggesting that a teacher's race can be analyzed interpersonally (i.e., individual), with what happens within the teacher's school building (group/intergroup), and within the school division (organization). Ultimately, the experiences and career outcomes for individuals within an organization are influenced by the diversity climate of the organization (Cox, 1994).

The use of Cox's CDO model is well suited for examining the experiences of Black special education teachers, because intraorganizational (i.e., school) forces of diversity may be used to explain concerns that lead to decisions to quit the teaching profession. Some researchers have reached conclusions that diversity can become a source of conflict for personnel if managed ineffectively or if diversity concerns are avoided within the organization (Cox, 1993; Mendonsa, 1999). For example, Cose (1993) used the CDO framework in a study examining
Blacks working in a majority White organization. Cose found many of the Black workers faced issues of racism and perceptions of difficult work environments that influenced their job satisfaction and, ultimately, these issues led to their decisions to quit working for the organization. In the current study, I applied the CDO framework to the individual experiences of Black special education teachers to understand the factors that influenced their decision to leave their education careers. The use of the CDO model from the group and organization construct was important to consider, as an individual's identity can surface within multiple structures. Therefore, a connection concerning the personal identity (e.g., race, role) may exist that may be analyzed at each CDO level (individual, group, organization); hence, supporting the CDO model as a plausible framework for the current study.

\section{Purpose of the Study}

Although there are some attrition differences between White and Black teachers, we do not know the specific experiences that underlie attrition for Black special education teachers. The purpose of this study is to illustrate why Black early-career special education teachers quit their positions. Understanding the experiences of Black special education teachers may assist in the design of preservice and in-service recruitment and retention strategies to increase the pool of these teachers. In general, the current qualitative study was designed to address a gap in the literature that highlights the experiences of Black teachers and the reasons that they decide to leave their positions as special education teachers. More specifically, the following research question was used to direct the current study:

Research Question: What are the experiences of early-career Black special education teachers that lead to their decision to quit?

\section{Method}

The current study was designed to examine the experiences of Black special education teachers who, during their early years of teaching in public 
LaRon A. Scott, AJERR, 2020; 5:79

schools, terminated their employment. A phenomenological research framework was used to conduct qualitative interviews of the participants. Creswell (2013) explained phenomenological research as a method of finding the core experi- ences of individuals concerning an issue to create meaning. In this context, this research method allowed me to identify and understand the meaning of the common issues relative to the participants' experiences (Creswell, 2013; Langdridge, 2007).

Table 1 Participant Demographics

\begin{tabular}{|c|c|c|c|c|c|c|c|}
\hline Pseudonym & Age & Sex & $\begin{array}{l}\text { Years of } \\
\text { Teaching }\end{array}$ & Grade Level & $\begin{array}{l}\text { Disability Category } \\
\text { of Students }\end{array}$ & $\begin{array}{l}\text { School District Lo- } \\
\text { cation }\end{array}$ & $\begin{array}{l}\text { Unique Demographics Infor- } \\
\text { mation of Participant }\end{array}$ \\
\hline Stacey & 28 & $F$ & 1 & Elementary & Autism & $\begin{array}{l}\text { Urban/ } \\
\text { Suburban (serving } \\
59,000 \text { students) }\end{array}$ & $\begin{array}{l}\text { One of three Black teachers in } \\
\text { school building; enrolled in al- } \\
\text { ternative pathway program to } \\
\text { completing certification }\end{array}$ \\
\hline Davonna & 26 & $F$ & 1 & Elementary & High Incidence & $\begin{array}{l}\text { Urban/ Suburban } \\
\text { (serving } 50,000 \text { stu- } \\
\text { dents) }\end{array}$ & $\begin{array}{l}\text { Career switcher; One of two } \\
\text { Black teachers in school build- } \\
\text { ing }\end{array}$ \\
\hline Keisha & 30 & $\mathrm{~F}$ & 1 & Middle & SLD & $\begin{array}{l}\text { Urban/ Suburban } \\
\text { (serving 50,000 stu- } \\
\text { dents) }\end{array}$ & $\begin{array}{l}\text { Career switcher; recently com- } \\
\text { pleted master's degree in spe- } \\
\text { cial education; One of eight } \\
\text { teachers of color in school } \\
\text { building }\end{array}$ \\
\hline Craig & 25 & M & 1 & Middle & High Incidence & $\begin{array}{l}\text { Urban/ Suburban } \\
\text { (serving 50,000 stu- } \\
\text { dents) }\end{array}$ & $\begin{array}{l}\text { Master's degree in education; } \\
\text { floated around school to sup- } \\
\text { port multiple general education } \\
\text { teachers; one of ten teachers of } \\
\text { color in school building }\end{array}$ \\
\hline Robin & 34 & $\mathrm{~F}$ & 1 & High & ID & $\begin{array}{l}\text { Urban (serving } \\
24,000 \text { students) }\end{array}$ & $\begin{array}{l}\text { Career switcher; enrolled in al- } \\
\text { ternative pathway program to } \\
\text { completing certification; one of } \\
25 \text { teachers of color in school } \\
\text { building }\end{array}$ \\
\hline Melvin & 38 & M & 3 & High & High Incidence & $\begin{array}{l}\text { Urban/ Suburban } \\
\text { (serving } 52,000 \text { stu- } \\
\text { dents) }\end{array}$ & $\begin{array}{l}\text { Career switcher; one of four } \\
\text { teachers of color in school } \\
\text { building }\end{array}$ \\
\hline Marlena & 37 & $\mathrm{~F}$ & 2 & Middle & EBD & $\begin{array}{l}\text { Urban (serving } \\
24,000 \text { students) }\end{array}$ & $\begin{array}{l}\text { Enrolled in alternative pathway } \\
\text { program to completing certifica- } \\
\text { tion; one of } 14 \text { teachers of color } \\
\text { in school building }\end{array}$ \\
\hline Kevin & 33 & M & 1 & High & EBD & $\begin{array}{l}\text { Urban/ Suburban } \\
\text { (serving } 50,000 \text { stu- } \\
\text { dents) }\end{array}$ & $\begin{array}{l}\text { One of five Black teachers in } \\
\text { school building }\end{array}$ \\
\hline Karen & 33 & $F$ & 2 & Elementary & High Incidence & $\begin{array}{l}\text { Urban (serving } \\
50,000 \text { students) }\end{array}$ & $\begin{array}{l}\text { Enrolled in alternative pathway } \\
\text { program to completing certifica- } \\
\text { tion; One of two Black teachers } \\
\text { in school building }\end{array}$ \\
\hline Charles & 29 & M & 2 & High & ID & $\begin{array}{l}\text { Urban (serving } 5300 \\
\text { students) }\end{array}$ & $\begin{array}{l}\text { One of eight Black teachers in } \\
\text { school building }\end{array}$ \\
\hline
\end{tabular}

Note. Within school teacher ratios were self-reported by participants. This information was approximated and no checks for accuracy were concluded by the researcher. $\mathrm{F}$ = female; $\mathrm{SLD}=$ specific learning disability; $\mathrm{EBD}=$ emotional behavioral disorder; ID = intellectual disability

\section{Participants}

A purposive sampling method was used to identify and select teachers who met the following criteria (Creswell, 2013): (a) terminated their careers after one, two, or three years of teaching; and (b) identified as Black special education teachers. A maximum of three years of teaching was selected because that is when non-probationary status is typically attained for teachers in the geographical area chosen for the current study. Five participants were initially recruited based on contacts with school principals, then a 
snowball sampling method was used to solicit additional participants (Merriam, 2002). Specifically, after interviews with the initial five participants, I asked for the name or contact information of other early-career Black special education teachers who met the criteria and who might be interested in the research study. The snowball method resulted in another eight possible participants, of whom an additional five agreed to participate. Three of the eight possible participants did not meet the criteria because they were transferring to another school district; thus, a final total of 10 participants agreed to be included in the current study.

Table 1 provides an overview of participant demographics and teaching history. For the total sample, $60 \%(n=6)$ were female and $(40 \% ; n=$ 4) were male. Participants were between the ages of 24 and 38 years of age, and represented practicing teachers at the elementary $(n=3)$, middle $(n=3)$, and high school $(n=4)$ levels in four different school districts in rural, urban, and suburban locations across the Southeast region of the United States. On average, the participants spent one and a half years as special education teachers. Four teachers were enrolled in coursework to finish their teaching endorsement in special education (i.e., provisionally licensed), while simultaneously employed as fulltime special education teachers. Overall, the four teachers completed six courses towards their license in special education, and needed approximately seven or more courses, in addition to student teaching, to complete their preparation programs. The other six participants were full-time licensed special education teachers.

\section{Data Collection Process}

Data collection started with individual semistructured interviews of participants. Participants received a consent form with the purpose of the study and were offered time to respond to questions regarding the study. Information on participants' backgrounds was collected through a demographic survey.
The research protocol was piloted with four doctoral candidates to ensure that information was clear and aligned with the focus of the current study. One overarching interview question was removed based on the candidates' feedback that the question was repetitive. Interview questions were connected to the conceptual framework and based on: (a) personal experiences, (b) school-related experiences, and (c) other factors that may have influenced participants' decisions to quit their teaching positions. The following are the main questions that participants were asked during the interviews: (a) What personal experiences led to your decision to leave your job as a special education teacher? (b) What schoollevel factors impacted your decision to leave your job and the special education teaching profession? (c) How did experiences within your school division impact your decision to leave the special education profession? Individual interviews lasted an average of 75 minutes each and were conducted in a private office at a time requested by each participant. With permission from the participants, the interviews were audio recorded and later transcribed by hand onto an interview protocol document.

\section{Trustworthiness}

Several strategies were used to ensure trustworthiness of the qualitative process. First, bracketing was utilized as a process to understand bias during the interaction with the participants and during the data analysis process. Rolls and Relf (2006) described one method of bracketing as engaging in interviews with an outside reviewer for challenging preconceptions and biases. Creswell (2003) described the role of the external reviewer as the examiner whose purpose is to provide a final assessment of the study. The external reviewer for the current study was a doctoral candidate with experience as a public school teacher and administrator whose role dealt with hiring, terminating, coaching and evaluating special education teachers. Therefore, I debriefed with the external reviewer before, during, and after data collection to remain partial during data collection and analysis (Rolls \& Relf, 
2006). This external reviewer was able to ask specific questions and make logical inferences based on the experiences of the teachers and the findings as interpreted by the researcher.

Creswell (2013) described clarification of bias as a self-reflective process that creates an open and honest dialogue with readers. Since I am a Black male full-time special education assistant professor with experience as a special education teacher, it was important to share this background information with participants. However, different from the participants, I did not quit my special education teaching job but became a special education department leader where part of the role was to provide support to other teachers. I also engaged in member checking, an important process to determine the accuracy of the interview notes (Merriam, 2002). Participants received the transcript of the interviews with final instructions to comment on accuracy of the transcript and interpretation of the themes (Merriam, 2002). Each participant authenticated the transcript and final themes, and no changes were requested.

\section{Data Analysis}

Creswell (2007) described a common procedure for data analysis that included a method for organizing and interpreting the meaning of phenomenological qualitative data. I followed the common process, beginning with going through the data and extracting significant quotes of from the participants (Creswell, 2007). Next, I labeled the relevant words, phrases, and other similar statements in the transcripts, coding the most important data that emerged, and creating and organizing final categories. Hierarchies among the categories were created based on the essence of participants' experiences and frequency of the findings. Data saturation was reached when both I and the external reviewer agreed that there was no additional variation in the data to extract for codes (Brod et al., 2009). Finally, the external reviewer enhanced the accuracy of the findings by asking questions regarding why certain decisions were made about the findings of the study and verifying the coding scheme.

\section{Results}

Four themes emerged based on participants' experiences of 10 early-career Black special education teachers and the influences that led to their decisions to quit their teaching positions. Each participant contributed perspectives related to the following four themes representing their decisions to quit: (a) inadequate mentoring, (b) role abuse, (c) cultural insensitivity, and (d) inadequate resources. Excerpts from participants' interviews are presented based on the individual, group, and organizational factors that are significant in showing the hardships encountered as a teacher. As a result, the relief experienced by the participants when they made the decision to quit is presented, in addition to the relationship to each theme. Examples of these experiences, which ultimately contributed to participants' decisions to quit their teaching positions, are presented in the excerpts from each participant's interview to illustrate these themes. Pseudonyms are used throughout to protect the anonymity of the study participants.

\section{Inadequate Mentor Support}

Each participant described being assigned a peer mentor ( $n=1$ white male mentor; 2 Black female, 7 white female mentors) by the school district officials as a contractual requirement of employment. Participants recounted peer mentor experiences at the group (i.e., school) and organizational (i.e., school district) level that contributed to their decisions to quit their teaching positions. Two participants reported having "strong mentors," and often reported positive experiences that contributed to their adjustment as an early-career special education teacher. Participants with "weak mentors" reported more negative experiences that influenced their decision to leave. Regardless of whether the mentoring experience was positive or negative, all participants noted that a mentor might have a significant influence on the culture and climate at the group and organizational levels (i.e., participant's school or school district), and ultimately 
contribute to a teacher making the decision to quit. Stacey, a first-year special education teacher, spoke about her negative experiences with her mentor, who she perceived as weak:

I could not believe that my mentor was actually respected in my building. She was mean and nasty to me. She was impatient and was easily frustrated by any mistake that I would make. I had to explain to her several times that this was my first year and I was trying my hardest. I felt like she often looked down on me. That she would insert her power over me. Others [colleagues on her grade level] saw how nasty she was as well. I sometimes felt like it was because I was the Black girl in the team. I can't say for sure though. They [colleagues on her team] just ignored her - but I couldn't. They were used to her negative energy. But they also said that she was more critical of me than she ever was to them. I could not stay around any longer with someone who was treating me nasty for no reason whatsoever.

Davonna, discussed early friction with her mentor who she believed was hard on her based on pressure she [the mentor] received from the school principal. She shared that:

She [her mentor] was sometimes nice and sometimes not very nice to me. I remember having a meeting with her where I just broke down crying because she was not listening to me. She [her mentor] said that she is only tough on me because she believes that I can do better, and if I don't do better, then the principal will call her [the mentor] to the carpet for not whipping me in shape. It was just a negative school environment from the principal to the mentor. I am someone with good energy and a good spirit. They [principal and mentor] just beat it [good spirit] out of me. I could no longer work with people who clearly did not care to truly support me the way I needed to be supported.
Challenging the negative experiences of eight of the participants, two participants noted positive experiences with their mentor. Keisha, shared that her mentor was a young Black woman who graduated from the program in which she was currently enrolled. Keisha stated, "my mentor knew what I had to deal with, so she was approachable and knew how to fix my issues." Keisha continued, "While my mentor was busy, she would make time for me because she saw herself in me-it could be because we are both young, Black, and had similar experiences."

Craig, also shared an experience about his mentor. Although Craig had a positive experience with his Black female mentor, the relationship created an "internal conflict in his own mind" that helped to influence his decision to leave his teaching position. Craig stated:

My mentor was a sweetheart. She was fun and knowledgeable. She really knew the field of special education and the students and families really liked her. I enjoyed working for her. But you can tell that she was being taken advantage of by everyone in the department and school. She was working until midnight and through the weekends. She would send emails all through the night. It was only three full-time special education teachers in my building and she would warn me that once I'm off probation that the principal would be assigning me more responsibilities like her. She was definitely trying to get me ready for what was to comebut it also scared me because I saw all of the additional responsibilities that she had, and I could not handle any more. I decided to leave before things got too crazy. I spoke with her about it and she supported me $100 \%$ and told me that if she could quit that she would as well.

Three participants shared experiences of having little-to-no contact with their mentors during their term. Robin, a first-year high school teacher, shared: 
I knew my mentor was too busy to support me because every time I would pass her in the hallway, she would apologize for not being able to spend any time with me. She was always busy. She was the department chair and I understand that she was busy. But, her being busy did little to nothing in terms of supporting me. I could do my job-but I also needed guidance and support, and as my mentor, she wasn't there for me.

Melvin, a third-year teacher, reported similar experiences as Robin:

My mentor was the department chair. He was always in meetings and I never saw the man. Good guy, but never [saw him]. It just added to my growing list of why I needed to leave out of there [school]. How are you going to get paid for being a mentor and don't provide any mentoring? The school district knew what was happening and all they could say is try to make time to meet. No support!

Despite teachers' varying experiences, each participant described the effect that a mentor had on their decisions to quit teaching special education. Several of the participants shared an understanding of the busy role and schedule of a mentor. Nonetheless, many participants understood the value of having a mentor who could provide positive support. It appears that mentors have a role in the decision of early career Black special education teachers to quit their teaching positions.

\section{Role Abuse}

For all participants, emotional and mental abuse associated with being a special education teacher was reported. Many $(n=6)$ communicated emotional and mental trauma based on their misunderstandings of the special education teacher role. For others $(n=3)$, emotional and mental abuse by colleagues within their schools and school system officials delimited their role and responsibilities, ultimately influencing the type of change they expected to impart to students in the classroom. Some participants $(n=$ 3) discussed the significance of being a Black special education teacher in classrooms with mostly Black students identified as having special needs, while White students participated in the general education classrooms. For example, Melvin stated, "it wasn't easy for me being a Black man and wanting more for my Black kids and feeling like I don't know how to really, I mean really, help them....it was hard emotionally for me just personally." Participants vented about constantly advocating for their students, whom they often perceived as mistreated in their schools.

Marlena, a second-year teacher talked about the emotional and mental abuse she experienced based on continually advocating for her students. Marlena perceived that general education teachers treated her poorly because she was a special education teacher. She stated:

You won't believe the type of abuse I faced by my colleagues whenever I wanted the same treatment for my students [special need students]. Because I was the special education teacher, they always saw me as lesser than. They saw me as the complainer. As the newbie who had no clue about what teaching really was about. They saw me as the teacher who wanted more for my students than other students had. This clearly was not true. I just wanted my students to have the same thing that other students had. I got so tired of having to fight for everything. And most of my students were Black. I'm convinced that if they were White and if their parents had the resources to fight the school that I would not have had to fight as hard. I just couldn't anymore. It was just emotionally and mentally draining. It really was.

Kevin, spoke about how he was responsible for handling the students who constantly misbehaved, even if they were not in his classroom or on his caseload. Kevin went on to say, 
They [general education colleagues at his school] would bring me all the little Black boys that were mouthing off or who were sleeping in their classes, or who weren't listening. Instead of trying to understand and build a relationship, they [colleagues] would rather kick them out their class and send them to me.....the only Black special education teacher in the building. I was tired of being the dump. I felt like I was the only one who had the patience to help these boys. But at the same time, a person gets fed up and tired of being the dump. That's not what special education is for. That's not what l'm for.

One participant reported that her final decision to quit was based on the abuse she experienced from her school principal. Karen disclosed that she has a child with a disability, which influenced her decision to become a special educator. However, she felt that her principal did not have the background to understand special education or her role as an educator. She felt "emotionally and physically abused as a special education teacher" because of the principal's "lack of respect and understanding of special education." Karen continued her point with stating:

My principal would refer to us [the special education teachers] as the other teachers. He would categorize us different than any other teacher in the school building. He would say "those kids" [students with disabilities] or "those teachers" [teachers of students with disabilities]. I was so sick of the abuse. Emotionally I could not take it anymore. I could not stand another day with a principal who wished they [students with disabilities and teachers of students with disabilities] were not in his building. I had to leave. I'm going to miss my kids though. I feel like the students needed me. I was one of only a handful of Black teachers that [who] students saw at that school. And now, well now, I don't know what they'll experience.
Emotional and mental trauma experienced by the teachers was a source of frustration that contributed to their decisions to quit their special education teaching positions. While their experiences varied, participants expressed frustrations with fulfilling what they perceived as their job responsibilities based on challenges that led to abuse and exhaustion. Despite their varying experiences, many of the participants voiced concerns about the students they taught, some of whom saw themselves as role models $(n=5)$ for the Black students in their respective schools. These teachers appeared concerned that without their presence in the schools the Black students with disabilities would experience some sort of discrimination.

\section{Cultural Insensitivity}

Cultural insensitivity was frequently indicated by participants $(n=5)$. The term cultural insensitivity is used in this study to describe microaggressions carried out by colleagues and building administrators, or critical observation of materials (e.g., curriculum and instructional content) that caused concerns for study participants. For example, Craig stated that he often felt "at odds" with seeing images of Confederate leaders like "Robert E. Lee," in textbooks or posters in his team taught classroom. While Stacey noted a situation in which she overheard a colleague during a school meeting talking about how parents in the community did not have the ability to read, and it contributed to students not returning their homework. Stacey stated:

I remember overhearing this teacher talking to another colleague during our school meeting that our students were mostly poor and their parents probably didn't know how to read. She said she sends home reminders to parents about helping their kids with their homework. I knew she was talking about the kids that are from the mostly urban areas. You know, the Black kids that [who] she is always writing up or sending to the office because they don't listen to her. Or, have 
reasons why they don't turn in their homework. These types of comments stuck with me and made me feel disgusted because I am one of those parents of a Black kid. I know people in those communities and they are just as smart as me, as smart as some of those teachers. You can't just judge people and communities off of a couple of bad situations.

Similarly, Kevin believed his side of the school district [self-described as the more urban side] that the students and the community members were perceived by his colleagues as poor and hopeless. Kevin stated:

You know, where I work the teachers really don't want to work on that side. They see the kids and community as poor and struggling. They [colleagues at the school and at other schools in his district] make negative comments about the parents and the students. They say things that really create a hostile work environment. Like, you want to say somethingbut you know that you have to work with these people. You know that they don't really want to be there [at the school] working with Brown kids. I'm not saying that this is all of them. But at the end of the day, I don't feel like I shared the same value of the community and kids that we were working for. I didn't feel included or shared the same expression as some of my colleagues and administrators. Even some of the administrators would make comments about how bad the kids were and that they were a product of their environment. Shoot, little did they know that I grew up in environments just like that. It was kind of insulting.

Even though not all participants' experienced cultural insensitivity as it pertained to race, some shared concerns of insensitivity regarding disability status. Davonna shared that she experienced pressure from colleagues and administrators to fix what was apparently wrong with the students with who she worked. She noted:
For the life of me, I could not understand why my team and principal wanted me to perform some sort of miracle with my students. They would make silly and uneducated comments about the learning abilities of my students. Like, we don't need to teach these skills because she's not going to pass the SOL [state assessment test] anyway. Can you get her to pass the test? If not, we need to just move on. You don't treat students with disabilities like an item that is only in the school to pass a test. These comments just got the best of me.

Black special educators described cultural insensitivity experiences that influenced their decisions to leave their teaching positions, and the lack of sensitivity in each experience provided the participants with more reasons to leave the field. The power of statements and experiences by colleagues and administrators created situations that remained with the participants. Keisha stated, "I could only put up with the insensitive comments by my colleagues but for so long."

\section{Inadequate Resources}

A person's financial resources, and school and school districts resources, seemed to emerge as a dominant theme that also influenced the Black special educators' decision to quit. Many $(n=5)$ of the participants talked about individual financial circumstances, including salary and repayment of student loans. Others $(n=4)$ discussed the lack of resources at their schools that required them to use their personal savings to support their teaching. Participants discussed the significance that financial resources had on their decisions to leave. For example, Charles, a second-year teacher, stated:

I don't understand why people think that because you can't afford to take out of your own personal pocket to buy supplies for your classroom and for students in your classroom, that you are suddenly not a worthy teacher. It's not that I'm not a worthy teacher. I'm poor myself and can't afford to buy everything that my class

https://escipub.com/american-journal-of-educational-research-and-reviews/ 
needs to function. But, some teachers and principals look at you like you are not the best teacher because you can't pay for things that you need to do your job. I got so sick of that.

Karen spoke about not coming from a wealthy background like some of her colleagues. She commented:

Some of my colleagues have husbands and parents with money. I am a single mother with two kids. Not that I'm complaining. I'm fine. But, I have student loans. Some of my colleagues, and yes, they were mostly White, parents paid for them to go to school. My income goes to tuition and bills. I don't have the same sense of security that they do. And they understood that, but it was still hard to manage off of a $\$ 43,000$ salary. After I paid bills, I soon realized that I needed a second job. And when student loans kick in....there is no way that I can afford the lifestyle that I anticipated on a teacher's salary. It's just sad because I feel like I'm a good teacher.

Craig also expressed financial concerns. Craig commented:

My school wanted me to switch to teach science for my second year. This is after building up my stock-pile and spending my own money on resources to teach math during my first year. I thought I would be in better shape for my second year. Now, to think about starting all over again and having to buy stuff to teach content that I was not familiar with... it was just not worth it to me. I can't keep affording to spend money out of my own pocket each year. It's ridiculous. I'm only making $\$ 15$ an hour after you calculate all the time I put into work each week, and then I have to buy stuff for lessons all the time.... just can't. It makes me sad because I'm a good teacher and I love my students, but I just can't afford to teach anymore.
The participants expressed clear concerns about the limited finances and resources as teachers. While many participants discussed limited resources within their schools, others made statements about their earnings and how they could not afford to teach. It is clear from the participant statements that financial concerns had a role in their decisions to quit.

\section{Discussion}

The purpose of this study was to add to the literature regarding the recruitment and retention of Black teachers, particularly in areas of shortage, such as special education. Existing literature on special education teacher attrition is mostly quantitative in nature and very rarely includes information about attrition relative to teacher's race (e.g., Billingsley \& Bettini, 2019 ; Haberman, 2004). From a qualitative perspective, the current study may provide more context about teacher attrition specifically related to Black special education teachers. By inquiring directly about the experiences of the early-career special educators, inferences may be drawn to assist in the retention of Black special education teachers. Even though the current study is limited in scope, other researchers interested in the topic can build and expand upon the themes identified.

\section{Cultural Diversity in Organization Issues}

The teachers in the current study experienced several challenges within their schools and school districts that can be explained as issues of race at the individual, group, and organizational levels where, according to the CDO model by Cox (1994), such challenges may be placed on teachers of color (the minority group) by the predominant culture. The experiences noted by the participants are consistent with findings from other studies about Black teacher's experiences (Griffin \& Tackie, 2016; Haberman, 2004; Gutierrez y Muhs et al., 2012). For example, Griffin and Tackie reiterated that racial discrimination and stereotypes exist in schools and in school systems, creating damaging conditions that affect Black teachers. Race-related chal- 
lenges in the education setting can be particularly salient for Blacks considering historical issues about school desegregation and disproportionality in discipline and special education placement. In the current study, some teachers described experiencing interpersonal conflict arising from factors at the individual, school, and school district levels, thus reinforcing the principles of the CDO model (Cox, 1994). For instance, at the individual level, Melvin put added pressure on himself as a Black man to positively impact outcomes for his Black students. Moreover, participants like Stacey explained that after overhearing a colleague stereotype who she perceived were the "Black parents and students" in her mostly Black school district, that this created barriers to her teaching longevity. Kevin was exposed to derogatory comments made by his colleagues at his school and at other schools in his district. Instances like those experienced by Melvin, Stacey and Kevin confirmed damaging encounters at the individual, group, and organizational level, which supports Cox's model that a person's race can be analyzed at the three levels, and how the diversity climate within an organization can adversely influence an individual's experiences and career outcome.

While past research indicated that special education teacher attrition is often related to a number of factors (e.g., personal circumstances, administrative support, certification status; Billingsley \& Bettini, 2019), other research has indicated that teachers of color may leave for reasons that may be more culturally grounded (unfair testing of students of color, visibility of other teachers of color, etc.; Haberman, 2004). Results of this research support the notion that attrition for early career Black special education teachers are entrenched in contextual factors such as school diversity, and race-related issues. While many teachers in the current study started their careers as special education teachers with hopes of making a significant positive influence on the lives of children with disabilities, serious challenges about the diversity of the organizational climate had a role in the participants choosing to quit the profession earlier than preferred.

Despite the short supply of teachers of color, and teacher attrition issues, early-career Black special education teachers can have success and retain remain in special education teacher positions for the long term. However, it will be difficult for these teachers to move into the second phase of their teaching careers if they are continually faced with barriers such as limited mentor support and cultural insensitivity. Participants like Robin expressed belief in her abilities to be a good special education teacher; however, she desired critical support from a mentor to feel comfortable and confident in her role. Stacey voiced that her White mentor imparted power over her and influenced her mentor/mentee relationship. Keisha believed that her Black female mentor was relatable and made the mentoring process more enjoyable for her. Gay (1995) posited that mentors should not simply be good teachers, but adults able to work effectively and efficiently with the individual being mentored. Thomas (1989) found based on a study regarding cross-racial mentoring that when Whites mentored Blacks, stereotypical behaviors on the part of the White mentor existed; however, the behaviors diminished when Blacks mentored Whites. The three participant examples were not to suggest that only Blacks should mentor Blacks, but used to illustrate how the dominant culture can place barriers for minorities (Cox, 1994) that contribute to their decisions to quit.

Lastly, study participants experienced individual and systemic challenges regarding personal and school-related resources that influenced their decisions to quit. Previous researchers pointed out that a teacher's pay affects their decision to quit (Imazeki, 2005) particularly, for novice teachers (Gritz \& Theobald, 1996). While prior research suggested higher salaries were associated with higher retention rates for teachers (Guarino et al., 2006), it is important to consider salaries with other contextual factors (e.g., school and district financial conditions) faced by 
participants. For example, many of the participants in the current study discussed the lack of resources at their schools and within their school districts. The lack of resources often meant that they had to spend personal money from their income on supplies for their classrooms and students. Craig and Charles expressed frustration with spending their personal income on school supplies. For Karen, her White colleagues were privileged coming from wealthy backgrounds and families, which put her at a disadvantage for becoming a special education teacher because, unlike them, she had personal debt from student loans to become a special education teacher. The disparity of student loan debt between Black and White students has been noted in research (Goldrick-Rab, \& Kelchen, 2015), and was an important issue when considering intergroup identity in the current study. For example, though unintentional, intergroup conflict at the school level that occurred between Karen and her White teacher colleagues was simply another barrier placed on teachers of color by the predominant culture. The conflict created a barrier and eventually added to a growing list of why Karen and perhaps other Black special education teachers quit.

\section{Limitations}

The current study had several major limitations. First, this study was limited to 10 Black special education teachers. Lincoln and Guba (1985) postulated that it is the responsibility of the reader to consider the transferability of the research study based on the sufficient contextual information provided in the study. Therefore, true to qualitative research, findings may not be generalizable to other racial/ethnic diverse groups. Although every attempt was made to provide a rich description of the 10 participants and the contextual factors associated with the study, other investigators or stakeholders should consider if their conditions are similar to conditions in the current study and then judge the degree of transferability.

A second limitation involved the fact that not all the teachers were fully licensed at the time of this study. Even though the four participants did not cite working on their license/degree as factors leading to their decisions to quit, some research indicates teachers who are not fully certified leave at higher rates than certified teachers (Baines, 2006; Carver-Thomas \& Darling-Hammond, 2017; Fisk et al., 2001). Finally, the experiences conveyed in the current study were contextually bound to the Black special education teachers in their respective schools and school districts. For instance, the problems of resources and mentoring addressed by participants may be specific to instances within their respective schools and school districts and may not be relevant to attrition in different contexts.

\section{Implications and Directors for Future Re- search}

Recruitment and retention as it pertains to teacher diversity in special education is a complex issue. The current study identified many issues that challenge the career paths of Black special education teachers. These findings expand previous research regarding attrition issues of teachers in special education overall (Billingsley \& Billingsley, 2019) and the complex attrition issues of teachers of color (Haberman, 2004). The four themes identified (i.e., inadequate mentoring, role abuse, cultural insensitivity, and inadequate resources) may provide a way forward to retain Black special education teachers.

The participants needed more guidance and support from their mentors but came up against mentors who did not have (or make) the time necessary or who were responding to demands from the administration. It seems obvious but bears stating that mentors need specific training as well as allotting mentors the time and opportunity to build positive relationships with their mentees. Given that White teachers typically outnumber Black teachers, mentor training should take on the difficult but critical issues of race.

A need exists to provide cultural sensitivity training within school organizations. As demographic shifts occur with the student and teacher 
populations, school district officials will need to consider adopting school reform models that will include addressing cultural awareness and sensitivity to improve school climate and eliminate the intentional or unintentional instances of microaggressions occurring at all levels. Additionally, as participants noted emotional and mental abuse associated with their role as special education teachers, it is vital that stakeholders within school organizations (e.g., principals, general education teachers) are aware of the roles and responsibilities of special education teachers, and any biases and stereotypes against the teachers are eradicated. Furthermore, increasing teacher pay and reducing teacher debt should be addressed. For example, a program that reduces debt for teachers who stay at least three years may reduce attrition of Black special education teachers. School and district level officials may potentially provide financial incentives for special education teachers, particularly for teachers of color. Results from the current study indicate that more work is needed to improve the experiences of Black teachers, particularly Black special education teachers, to retain them in special education teaching positions. Surely, it will be important to remove barriers to mentor support, role abuse, cultural insensitivity, and resources faced by the group. Removing organizational barriers for teachers of color may provide for experiences that are more positive and ultimately lead to greater retention of Black special education teachers. Future research should continue to address factors that influence Black special education teacher attrition, and other school-related issues that influence retention. Future work could also examine the effects of gender alongside race with groups of special education teachers. Futhermore, efforts should be focused on the role of mentors, principals, general education teachers, families, students, and other stakeholders as individuals, groups, and within organizational contexts that have a role in Black special education teacher attrition. Finally, further research examining the perceptions of Black special educators who persist and stay in their positions, despite facing similar challenges as teachers in this current study, may lead to more understanding of Black special education teacher retention.

\section{Conflicts}

I have no conflicts of interest to disclose.

\section{References}

1. Achinstein, B., Ogawa, R., Sexton, D., \& Freitas, C. (2010). Retaining teachers of color: A pressing problem and a potential strategy for "hard-to-staff" schools. Review of Educational Research, 80(1), 71-107.

2. Adera, B. A., \& Bullock, L. M. (2010). Job stressors and teacher job satisfaction in programs serving students with emotional and behavioral disorders. Emotional and Behavioral Difficulties, 15(1), 5-14.

3. Baines, L. (2006). Deconstructing teacher certification. Phi Delta Kappan, 88(4), 326- 328.

4. Billingsley, B. S., Bettini, E. A., \& Williams, T. O. (2019). Teacher racial/ethnic diversity: Distribution of special and general educators of color across schools. Remedial and Special Education, 40(4), 199-212. https://doi.org/10.1177/074193 2517733047

5. Boe, E., Cook, L. H., \& Sunderland, R. J. (2008). Teacher turnover: Examining exit attrition, teaching area transfer, and school migration. Exceptional Children, 75(1), 7-31.

6. Brod, M., Tesler, L.E., \& Christensen, T.L. (2009). Qualitative research and content validity: Developing best practices based on science and experience. Quality of Life Research, 18, 1263-1278.

7. Carver-Thomas, D. (2018). Diversifying the teaching profession: How to recruit and retain teachers of color. Palo Alto, CA: Learning Policy Institute.

8. Carver-Thomas, D. \& Darling-Hammond, L. (2017). Teacher turnover: Why it matters and what we can do about it. Palo Alto, CA: Learning Policy Institute.

9. Cartledge, G., Gardner, R. III, \& Ford, D. Y. (2009). Diverse learners with exceptionalities: Culturally responsive teaching in the inclusive classroom. Upper Saddle River, NJ: Pearson.

10. Cherng, H.-Y. S., \& Halpin, P. (2016). The importance of minority teachers: Student perceptions of minority versus White teachers. Educational Research, 45(7), 407-420.

11. Conley, S., \& You. S. (2016). Key influences special education teachers' intentions to leave: The effects of administrative support and teacher team 
LaRon A. Scott, AJERR, 2020; 5:79

efficacy in a mediational model. Educational Management Administration \& Leadership, 45(3), 521540.

12. Cormier, C., \& Scott, L.A. (in press). Castaways on Gilligan's island: Special education

13. teachers of color advocating for an inclusive workspace. TEACHING Exceptional Children

14. Cose, E. (1993). The rage of a privileged class. New York: Harper Perennial.

15. Cox, T. (1993). Cultural diversity in organizations: Theory, research, \& practice. San Francisco, CA: Berrett-Koehler.

16. Cox, T. (1994). Cultural diversity in organizations theory, research, and practice. San Francisco: Berrett-Koehler.

17. Creswell, J. (2007). Qualitative inquiry \& research design: Choosing among five approaches. Thousand Oaks, CA: Sage Publications.

18. Creswell, J. (2003). Research design: Qualitative, quantitative, and mixed-methods approaches ( $2^{\text {nd }}$ Edition). Thousand Oaks, CA: Sage Publications.

19. Creswell, J.W. (2013). Qualitative Inquiry \& Research Design: Choosing Among the Five Approaches. Thousand Oaks, CA: SAGE Publications, Inc. (pp. 77-83)

20. Dee, T. (2004). Teachers, race, and student achievement in a randomized experiment. The Review of Economics and Statistics, 86(1), 195210.

21. Easton-Brooks, D. (2019). Ethnic Matching: Academic Success of Students of Color. Lanham, MD: Rowman \& Littlefield Publishers.

22. Egalite, A.J., \& Kisida, B. (2018). The effects of teachers match on student academic perception and attitudes. Educational Evaluation and Policy Analysis, 40(1), 59-81.

23. Egalite, A. J., Kisida, B., \& Winters, M. A. (2015). Representation in the classroom: The effect of own-race teachers on student achievement. Economics of Education Review, 45, 44- 52.

24. Fisk, C. P, Prowda, P., \& Beaudin, B. (2001, April). Are we keeping the best and brightest? A study of beginning teacher attrition in Connecticut. Paper presented at the annual conference American Educational Research Association Annual Meeting, Seattle, WA.

25. Ford, D. (2012). Culturally different students in special education: Looking backward to move forward. Exceptional Children, 78(4), 391-405.

26. Gay, G. (1995). Modeling and mentoring in urban teacher preparation. Education and Urban Society, 28(1), 103-118. doi:10.1177/0013124595028001008

27. Goldrick-Rab S., \& Kelchen, R.. (2015). Making sense of loan aversion: Evidence from Wisconsin. In K. Hollenback, \& M.H. Brad (Eds.), Student loans and the dynamics of debt (pp. 307-371). Kalamazoo, MI: W. E. Upjohn Institute for Employment Research

28. Goldring, R., Taie, S., \& Riddles, M. (2014). Teacher attrition and mobility: Results from the 2012-13 teacher follow-up survey (NCES 2014077). U.S. Department of Education. Washington, DC: National Center for Education Statistics. Retrieved from http://nces.ed.gov/pubsearch

29. Gershenson, S., Hart, C. M. D., Lindsay, C. A., \& Papageorge, N. W. (2017). The long-run impacts of same race teachers. Bonn, Germany: IZA Institute of Labor Economics. Discussion Paper Series.

30. Griffin, A., \& Tackie, H. (2016). Through our eyes: Perspectives and reflections from black teachers. Washington, DC: The Education Trust. https://edtrust.org/resource/eyes-perspectives-reflections-black-teachers.

31. Gritz, R., \& Theobald, N. (1996). The effects of school district spending priorities on length of stay in teaching. Journal of Human Resources, 31(3), 477-512.

32. Guarino, C. M., Santibañez, L., \& Daley, G. A. (2006). Teacher recruitment and retention: A review of the recent empirical literature. Review of Educational Research, 76(2), 173-208.

33. Gutiérrez y Muhs, G., Flores Niemann, Y., González, C.G., and Harris, A.P. (Eds.) (2012). Presumed Incompetent: The Intersections of Race and Class for Women in Academia. Logan, UT: Utah State University Press.

34. Haberman, M. (2004). Teacher burnout in black and white. The Haberman Educational Foundation.

35. Hastings, R. P., \& Brown, T. (2002). Coping strategies and the impact of challenging behaviors on special educators' burnout. Mental Retardation, 40, 148-156.

36. Henfield, M. (2013). School counseling for gifted Black males. Gifted Child Today, 36(1), 57-61. doi:10.1177/1076217512465287

37. Imazeki, J. (2005). Teacher salaries and teacher attrition. Economics of Education Review, 24(4), 431-449.

38. Ingersoll, R.M., \& May, H. (2011). Recruitment, retention and the minority teacher shortage. Consortium for Policy Research in Education. CPRE Research Report \#RR-69.

39. Jones-Goods, K. M., \& Grant, M. C. (2016, January 31). A phenomenological study of cultural responsiveness in special education. Journal of $R e-$ search Initiatives, 2(1), 17. Retrieved from http://digitalcommons.uncfsu.edu/jri/vol2/iss1/17/ 
LaRon A. Scott, AJERR, 2020; 5:79

40. U.S. Department of Education, National Center for Education Statistics. (2019). The conditions of education: Children and youth with disabilities The Condition of Education 2016 (NCES 2019-144). Retrieved from https://nces.ed.gov/programs/coe/indicator_cgg.asp.

41. Langdridge, D. (2007). Phenomenological psychology: Theory, research and method. London: Person Education Limited.

42. Lincoln, Y. S.,\& Guba, E .G. (1985). Naturalistic inquiry. Newbury Park, CA: Sage.

43. Lindsay, C. A., \& Hart, C. M. D., (2017). Exposure to same-race teachers and student disciplinary outcomes for Black students in North Carolina. Educational Evaluation and Policy Analysis, 39(3): 485-510.

44. Madsen, J., \& Mabokela, R. (2000). Organizational culture and its impact on African American teachers. American Educational Research Journal, 37(4), 849-876.

45. McLeskey, J., \& Billingsley, B. (2008). How does the quality and stability of the teaching force influence the research-to-practice gap?: A perspective on the teacher shortage in special education. $R e-$ medial and Special Education, 29(5), 293-305. doi: $10.1177 / 0741932507312010$

46. Mendonsa, R.M. (1999). Riding the waves of culture: Understanding cultural diversity in business. Human Resources Development Quarterly, 10(2), 185-188.

47. Merriam, S. B. A. (2002). Qualitative research in practice: Examples for discussion and analysis (1st ed.). San Francisco, CA: Jossey-Bass.

48. Moore, C. (2012). The role of school environment in teacher dissatisfaction among U.S. public school teachers. SAGE Open, 1(2), 1-16. doi: https://doi.org/10.1177/2158244012438888

49. Perrachione, B. A, Rosser, V.J., \& Petersen, G. J. (2008). Why do they stay? Elementary teachers' perceptions of job satisfaction and retention. The Professional Educator, 32(2), 25-41.

50. Plash, S., Piotrowski, C. (2006). Retention issues: A study of Alabama special education teachers. Education, 127, 125-128.

51. Redding, C. (2019). Student-teacher racial/ethnic matching on teacher perceptions of students and student academic and behavioral outcomes. Review of Educational Research, 89(4), 499-535.

52. Rolls, L., \& Relf, M. (2006). Bracketing interviews: Addressing methodological

53. challenges in qualitative interviewing in bereavement and palliative care.

54. Mortality, 11(3), 286-305.

55. Skaalvik, E. M., \& Skaalvik, S. (2007). Dimensions of teacher self-efficacy and relations with strain factors, perceived collective teacher efficacy, and teacher burnout. Journal of Educational Psychology, 99, 611-625.

56. Swars, S. L., Meyers, B., Mays, L. C., \& Lack, B. (2009). A two-dimensional model of teacher retention and mobility: Classroom teachers and their university partners take a closer look at a vexing problem. Journal of Teacher Education, 60, 168-183. doi:10.1177/0022487108329116.

57. Thoma, C. A., Cain, I., \& Walther-Thomas, C. (2015). National goals for the education of children and youth with intellectual and developmental disabilities: Honoring the past while moving forward. Inclusion, 3(4), 219-226.

58. Thomas, D. A. (1989). Mentoring and irrationality: The role of racial taboos. Human Resource Management, 28(2), 279-290.

59. U.S. Department of Education, National Center for Education Statistics, Common Core of Data (CCD), "Public Elementary/Secondary Universe Survey," 2015-2016.

60. U. S. Department of Education, Office of Planning, Evaluation and Policy Development, Policy and Program Studies Service. (2016). The State of Racial Diversity in the Educator Workforce, Washington, D.C. Retrieved from https://www2.ed.gov/rschstat/eval/ highered/racial-diversity/state-racial-diversityworkforce.pdf

61. Vannest, K. J., \& Hagan-Burke, S. (2010). Teacher time use in special education. Remedial and Special Education, 31, 126-142. 